\title{
Adsorptive Removal of Lead and Cadmium lons using Cross-Linked CMC Schiff Base: Isotherm, Kinetics and Catalytic Activity
}

\author{
P. MOGANAVALLY ${ }^{1}$, M. DEEPA $^{2 *}$, P. N. SUDHA ${ }^{3}$ and R. SURESH ${ }^{4}$ \\ ${ }^{1}$ Research and Development Centre, Bharathiyar University, Coimbatore, India. \\ ${ }^{2}$ Department of Chemistry, Muthurangam Govt. Arts College, Vellore, India. \\ ${ }^{3} \mathrm{PG} \&$ Research Department of Chemistry, D.K.M College for Women, Vellore, India. \\ ${ }^{4}$ Government Polytechnic College, Nagapadi, Thiruvannamalai, India. \\ ${ }^{*}$ Corresponding author E-Mail: deeparam79@gmail.com
}

http://dx.doi.org/10.13005/ojc/320150

(Received: January 21, 2016; Accepted: March 08, 2016)

\begin{abstract}
Water plays a vital role to human and other living organisms. Due to the effluent coming from chemical industries, the industrial activity, contamination of ground water level is goes on increasing nowadays. Therefore, there is a need to develop technologies that can remove toxic pollutants in wastewater. Hence the cross linked Carboxymethyl chitosan(CMC)/ 2,3-dimethoxy Benzaldehyde Schiff base complex has been synthesized and characterized by using FT-IR and SEM analysis. All these results revealed that cross linked Schiff base has formed with high adsorption capacity. The prepared effective adsorbent used for the removal of heavy metals like lead (II) and cadmium (II) ions from aqueous solution and the adsorption data follow the Freundlich model, which follows pseudo first order kinetics. Effect of various parameters like solution $\mathrm{pH}$, adsorbent dose and contact time for the removal of heavy metals has been studied. The synthesized sample undergoes catalytic oxidation process significantly at $24 \mathrm{hrs}$. The results showed that cross linked Schiff base is an effective, eco-friendly, low-cost adsorbent.
\end{abstract}

Key words: Carboxymethyl chitosan; Gluteraldehyde; adsorption; catalytic activity;

\section{INTRODUCTION}

Chitosan, the most abundant natural polysaccharide, is produced by the deacetylation of chitin which is one of the key constituents of the shells of crustaceans and a byproduct of the fishing industry. Chitosan is an inexpensive and renewable material with many applications in cosmetics, pharmaceuticals, food science and biotechnology 1-2. Due to the poor solubility of chitosan, Ocarboxymethyl chitosan, which is a water soluble chitosan derivative, have attracted much attention 
as it widened its applications. Carboxymethyl chitosan is not only a good solubility, but also possess unique chemical, physical and biological properties 3. Carboxymethyl chitosan is formed by means of carboxymethylation, as some of the $-\mathrm{OH}$ of chitosan were replaced by $-\mathrm{CH}_{2} \mathrm{COOH}$ groups. Therefore, the reactive ligands like $-\mathrm{COOH}$ and $-\mathrm{NH}_{2}$ groups are still ready to undergo chemical modifications to improve its physical properties. In comparison to chitosan, CMC has higher moisture absorption, retention, better biological, chelating and sorption properties ${ }^{4-6}$. Generally, Schiff based material exhibits wide range of applications, hence the water soluble CMC has to be modified into Schiff base with 2,3 -dimethoxy Benzaldehyde.

Crosslinking is another method adopted to improve the properties of Carboxymethyl chitosan Schiff bases. Crosslinking agents are generally structured in many forms like rings, straight chains, and branched chains. There are several crosslinking agents like gluteraldehyde, formaldehyde, glyoxal etc. In general, adsorption capacity decreases with the extent of crosslinking, as it decreases the reactive sites on the polymer. But in some cases it also improves the adsorption capacity, depending on the functional groups in the crosslinking agent ${ }^{7}$. The chitosan and chitosan crosslinked with gluteraldehyde has reported in the previous literatures ${ }^{8-9}$ and their application in the removal of heavy metals ${ }^{10}$ and biological property have been discussed. The metal selected for our study is lead and cadmium. Therefore in the present work, Chitosan modified to Carboxymethyl chitosan, by considering the solubility the modification made and to improve in applications, it has been crosslinked. Carboxymethyl chitosan /2,3-dimethoxy Benzaldehyde Schiff base was cross linked by using gluteraldehyde has been synthesized and characterized using the techniques like FT-IR, XRD, SEM, Catalytic activity and investigated for its adsorption capacity and its kinetics.

\section{MATERIALS AND METHODS}

Carboxymethyl chitosan were purchased from India Sea Foods, Cochin, Kerala, India. The aldehyde such as 2, 3- dimethoxy Benzaldehyde and gluteraldehyde were purchased from Sigma Aldrich, India. All the chemicals used were of analytical grade.

\section{Synthesis of Carboxymethyl chitosan Schiff Bases (CMC-SB)}

The Carboxymethyl chitosan Schiff base is prepared already and reported in the literature ${ }^{11}$.

\section{Synthesis of cross-linked Carboxymethyl chitosan Schiff Bases (CMC-SB)}

The synthesized Carboxymethyl chitosan Schiff base product was dissolved in water and stirred at room temperature for $30 \mathrm{~min}$. Then gluteraldehyde was added to the mixture. The mixture was stirred and heated at $60^{\circ} \mathrm{C}$ for $12 \mathrm{~h}$ under water bath heating. After cooling, the crude product was washed with ethanol to the point of colorless filtrate. The product was dried at $60^{\circ} \mathrm{C}$ in vacuum for $24 \mathrm{~h}^{12}$. The cross linked Carboxymethyl chitosan Schiff base (GLUCMC-SB) structure is shown in Figure-1.

\section{Characterization of CMC \& C-CMC Schiff base complex}

FT-IR spectroscopy was measured to determine the type of bonds. Fourier transform infrared spectra of CMC-Schiff base and its cross linked derivatives using KBR pellet method were recorded in the frequency range of $400-$ $4000 \mathrm{~cm}^{-1}$ using Thermo Nicolet AVATAR 330 spectrophotometer. $\mathrm{X}$ - ray diffractograms of samples were obtained using an $X$ - ray powder diffractometer (XRD - SHIMADZU XD - D1) with $\mathrm{Ni}$ - filter and $\mathrm{Cu}$ Ká radiation source. The relative intensity was recorded in the scattering range 2è, varying from $10^{\circ}$ to $90^{\circ}$. The surface morphology and cross section morphology of CMC- Schiff base and its cross-linked derivatives were observed with scanning electron microscopy to verify the compatibility of the mixtures of CMC-SB derivatives. To analyze the samples, the films were cut into pieces of various sizes and wiped with a thin gold - palladium layer by a sputter coater unit (UG - microtech, UCK field, UK) and the cross section topography was analyzed with Cambridge Stereoscan 440 Scanning Electron Microscope (Leica, Cambridge UK).

\section{Catalytic activity}

The oxidation of cyclohexane was performed under the aerobic conditions. $10 \mathrm{mmol} 30 \%$ hydrogen peroxide solution was added to the Schiff base complex $(0.05 \mathrm{~g})$ in $10 \mathrm{ml}$ of acetonitrile in a $25 \mathrm{ml}$ ûask equipped with a magnetic stirrer and ûtted with water condenser. With this reaction mixture, 
$5 \mathrm{mmol}$ of cyclohexane was added and allowed to stir magnetically under $70{ }^{\circ} \mathrm{C}$ at atmospheric pressure conditions for $12 \mathrm{~h}$. Aliquots were collected separately at $8 \mathrm{~h}$ and $12 \mathrm{~h}$ for the product analyses. Two separate blank experiments were also carried out, one without metal complex and one without $\mathrm{H}_{2} \mathrm{O}_{2}$, by keeping other experimental conditions unaltered to prove the importance of catalyst and $\mathrm{H}_{2} \mathrm{O}_{2}$ in the reaction. The collected product samples were analyzed with a Hewlett-Packard gas chromatogram (HP 6890) having FID detector. The conditions followed in the product analysis were, capillary column: HP-5, carrier gas: nitrogen, and ûow rate: $0.5 \mathrm{~cm}^{3} \mathrm{~min}^{-1}$. In the same way cross linked CMC Schiff base derivative also prepared.
The conversion percentage of cyclohexane was calculated as below:

$$
\begin{gathered}
\text { Conversion } \% \text { of cyclohexane }=100 \times[\text { Initial } \%- \\
\text { Final\%] } / \text { Initial\% }
\end{gathered}
$$

\section{Heavy metal removal by batch adsorption studies}

Synthetic solutions of $\mathrm{Pb}$ (II) ions and $\mathrm{Cd}$ (II) ions were taken in stopper bottles and agitated with schiff base and its crosslinked schiff base separately at $30^{\circ} \mathrm{C}$ in orbit shaker at fixed speed of $160 \mathrm{rpm}$. The extent of heavy metal removal was investigated separately by changing adsorbent dose, contact time
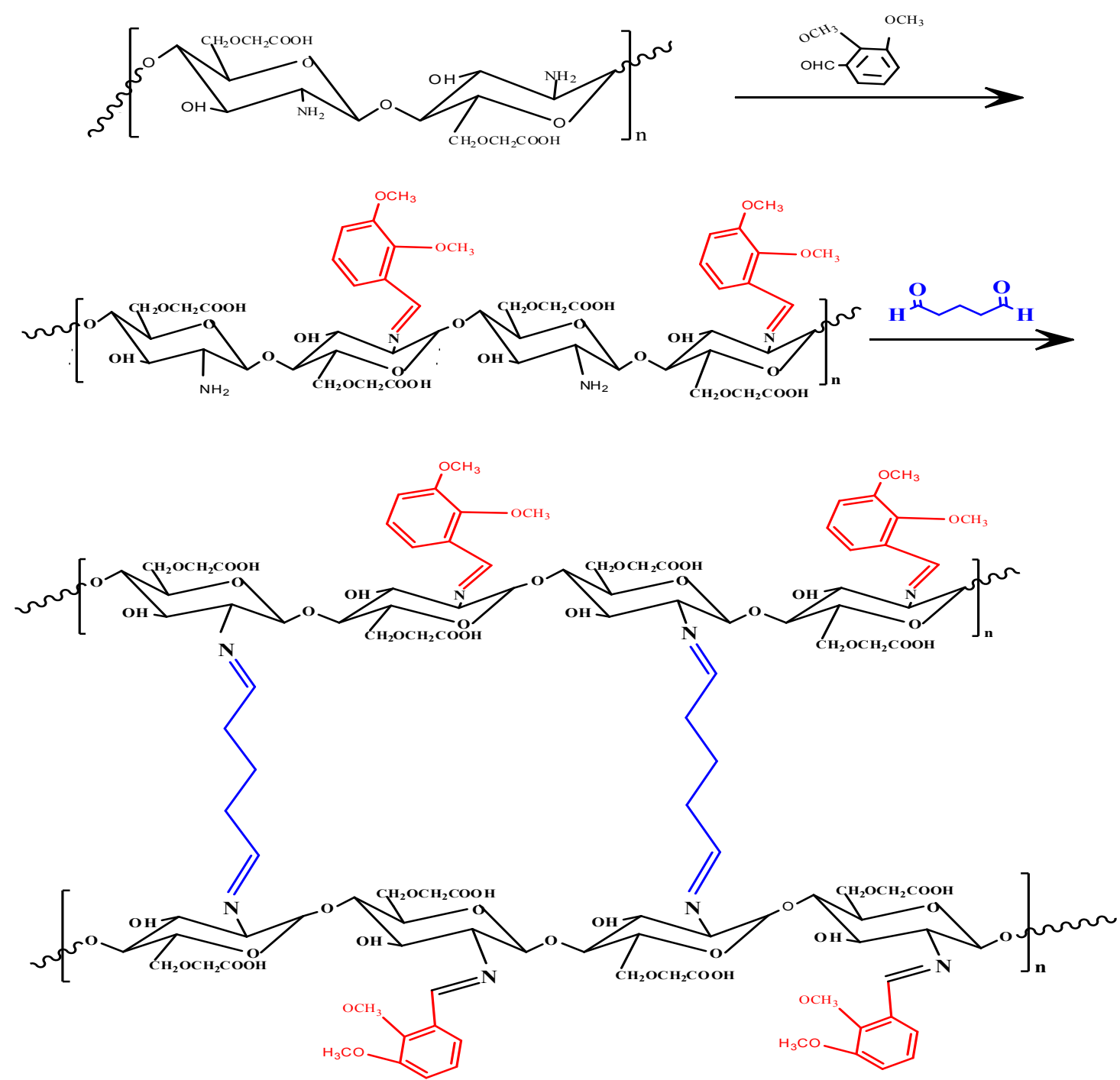

Fig. 1: Structure of CMC-SB and GLU-CMC-SB complex 
of shaking and changing $\mathrm{pH}$ of the solution. After attaining the equilibrium adsorbent was separated by filtration using filter paper and aqueous phase concentration of metal was determined with atomic adsorption spectrophotometer (Varian AAA 220 FS).

\section{Adsorption isotherm studies}

At the optimum conditions of adsorbent dose and $\mathrm{pH}$, the synthetic solutions of $\mathrm{Pb}$ ions were agitated for one hour at various initial concentrations and amount of unadsorbed lead in the filtrate were analysed. The same procedure is followed to analyse the $\mathrm{Cd}$ (II) ions. The values were fitted into Langmuir, Freundlich, Temkin and Dubinin - Radushkevich (D - R) adsorption isotherms.

\section{Langmuir adsorption isotherm}

In this study the following linearised form of the Langmuir isotherm was used.

$$
\mathrm{C}_{\text {eq }} / \mathrm{C}_{\text {ads }}=\mathrm{bC}_{\text {eq }} / \mathrm{K}_{\mathrm{L}}+1 / \mathrm{K}_{\mathrm{L}} \text { and } \mathrm{C}_{\max }=\mathrm{K}_{\mathrm{L}} / \mathrm{b}
$$

Where

$\mathrm{C}_{\text {ads }}=$ amount of metal ion adsorbed $(\mathrm{mg} / \mathrm{g})$

$\mathrm{C}_{\mathrm{eq}}=$ equilibrium concentration of metal ion in solution $\left(\mathrm{mg} / \mathrm{dm}^{3}\right)$

$\mathrm{K}_{\mathrm{L}}=$ =Langumir constant $\left(\mathrm{dm}^{3} / \mathrm{g}\right)$

$\mathrm{b}=$ Langumir constant $\left(\mathrm{dm}^{3} \cdot \mathrm{mg}\right)$

$\mathrm{C}_{\max }=$ maximum metal ion to adsorb onto $1 \mathrm{~g}$ chitosan $(\mathrm{mg} / \mathrm{g})$.

\section{Freundlich adsorption isotherm} expressed as:

The Freundlich equation which is used is

$$
\mathrm{C}_{\mathrm{ads}}=\mathrm{P} \mathrm{C}_{\mathrm{eq}}{ }^{1 / n}
$$

In and linearised form of the Freundlich equation was used.

$$
\log C_{\text {ads }}=\log P+1 / n \log C_{\text {eq }}
$$

where

$\mathrm{C}_{\text {ads }}=$ amount of metal ion adsorbed $(\mathrm{mg} / \mathrm{g})$

$\mathrm{C}_{\mathrm{eq}}=$ equilibrium concentration in solution $\left(\mathrm{mg} / \mathrm{dm}^{3}\right)$

$1 / \mathrm{n}=$ Freundlich constant $\left(\mathrm{mg}^{\mathrm{g}} \mathrm{g}^{-1}\right)$

$\mathrm{P}=$ Freundlich constant $\left(\mathrm{g} \cdot \mathrm{dm}^{-3}\right)$

\section{Temkin model}

The Temkin model is linearly represented and generally applied in the form:

$$
q e=B \ln A_{T}+B \ln C e
$$

Where $A$ and $B$ are the Temkin isotherm constant $(\mathrm{L} / \mathrm{g})$ and heat of sorption $(\mathrm{KJ} / \mathrm{mol})$ respectively. $R$ is the gas constant $(\mathrm{J} / \mathrm{mol} / \mathrm{k}), b$ is the Temkin isotherm constant linked to the energy parameter, $\mathrm{B}, \mathrm{T}$ is the absolute temperature in kelvin as shown on equation:

$\mathrm{b}=\mathrm{RT} / \mathrm{B}$

\section{Dubinin-Radhushkevich isotherm}

Dubinin - Radushkevich $(D-R)$ isotherm helps to determine the nature of bonding either physisorption (or) chemisorption,

$$
\ln \mathrm{q}_{\mathrm{e}}=\ln \mathrm{q}_{\mathrm{s}}-\mathrm{K}_{\mathrm{ad}} \varepsilon^{2}
$$

$\mathrm{q}_{\mathrm{m}}$ is the maximum adsorption capacity $(\mathrm{mg} / \mathrm{g}) \cdot \mathrm{K}_{\mathrm{ads}}$ is a D-R constant related to the energy of adsorption and å is the Polanyi potential.

$$
\varepsilon=R T \ln \left[1+\left(1 / C_{e}\right)\right]
$$

The mean free energy of adsorption (E) calculated using eqn,

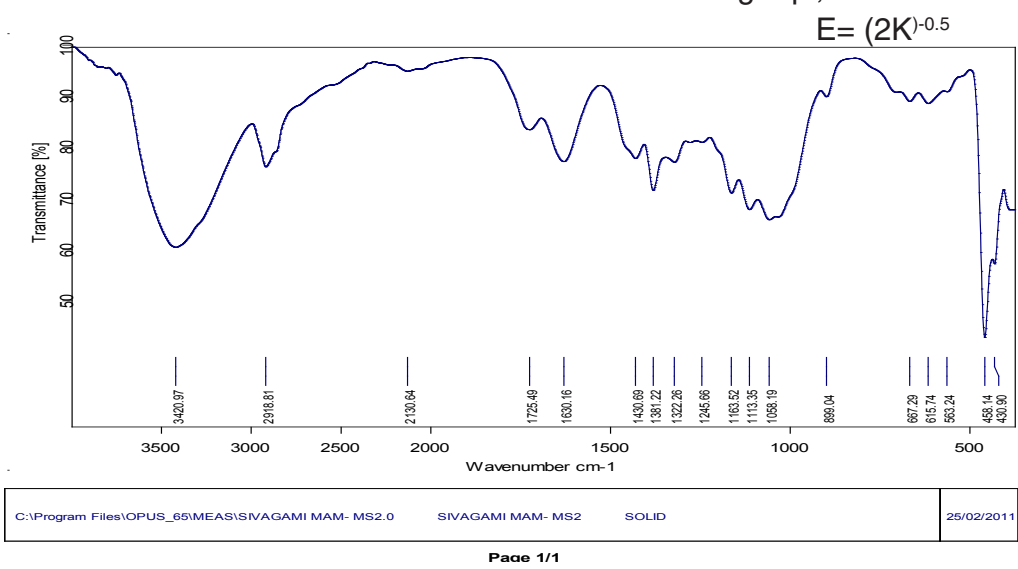

Fig. 2: FTIR spectrum of Carboxymethyl Chitosan 


\section{Kinetics Studies}

In the present study kinetics were calculated for both pseudo-first order, the pseudo second order kinetic models applied and expressed as follows.

\section{Pseudo-first order kinetics}

Rate expression is

$$
\log \left(q_{e}-q_{t}\right)=\log q_{e}-(k / 2.303) t
$$

$\mathrm{q}_{\mathrm{t}}$ and $\mathrm{q}_{\mathrm{e}}$ are the amounts of ion adsorbed at time $\mathrm{t}$ and at equilibrium $(\mathrm{mg} / \mathrm{g}), \mathrm{k}_{1}=$ rate constant $\left(\min ^{-1}\right)$

\section{Pseudo-Second order Kinetics}

Rate expression is

$$
t / q_{t}=1 / k_{2} q_{e}^{2}+t / q_{e}
$$
$\left(\mathrm{gmg}^{-1} \mathrm{~min}^{-1}\right)$.

where, $\mathrm{k}_{2}=$ second order kinetic constant

\section{RESULTS AND DISCUSSION}

\section{FTIR studies}

Figure-2, 3 and 4 shows the FT- IR spectrum of the Carboxymethyl chitosan (CMC) and Carboxymethyl chitosan/2,3-dimethoxy Benzaldehyde Schiff base (CMC-SB) and cross linked gluteraldehyde Schiff base (Glu-CMC-SB) complex. The spectrum shows a broad peak at 3420 and $3418 \mathrm{~cm}^{-1}$ for CMC and CMC-SB, but in case of cross linked Schiff base complex appeared at $3436 \mathrm{~cm}^{-1}$ slightly higher, which indicates the intermolecular hydrogen bond $\mathrm{O}-\mathrm{H}, \mathrm{N}-\mathrm{H}$ stretching and polymeric association with gluteraldehyde. The asymmetic $\mathrm{C}-\mathrm{H}$ stretching was indicated by the peak at $2918 \mathrm{~cm}^{-1}$ for CMC, $2921 \mathrm{~cm}^{-1}$ for CMC-SB, and $2928 \mathrm{~cm}^{-1}$ for Glu-CMC-SB, this corresponding peak shift to the higher position reveals the incorporation of aromatic $\mathrm{C}-\mathrm{H}$ bonds of aldehyde ${ }^{13}$.

The peak at $1725 \mathrm{~cm}^{-1}$ in $\mathrm{CMC}$ has shifted to the lower wavenumber $1604 \mathrm{~cm}^{-1}$ in CMC-SB and $1631 \mathrm{~cm}^{-1}$ in Glu-CMC-SB complex. This band is most probably composed of amide band of Carboxymethyl chitosan, $\mathrm{C}=\mathrm{N}$ stretching band of Schiff base were cross-linked with - $\mathrm{CHO}$ of gluteraldehyde ${ }^{14}$. Moreover, it is not observed any band at $\sim 1715$ related to free aldehyde group ${ }^{15}$. The absorption at $1418 \mathrm{~cm}^{-1}$ in Glu-CMC-SB represents the $-\mathrm{CH}$ - bending of $-\mathrm{CH}_{2}$ - in gluteraldehyde, which is not present in CMC-SB complex. The FTIR spectrum of CMC, CMC-SB and Glu-CMC-SB showed its characteristic Schiff base formation peaks were in the range of $1598-1650 \mathrm{~cm}^{-1}$, confirming the presence of imine bond was formed between -NH group of carboxymethyl chitosan matrix and with the $\mathrm{C}=\mathrm{O}$ group of gluteraldehyde. The decrease in the intensity of the peak for $-\mathrm{NH}_{2}$ group content, which indicates the participation of the amino group of the CMC polymer matrix with the aromatic aldehyde to form Schiff bases and crosslinked with gluteraldehyde ${ }^{16}$. All these characteristics prove the formation of crosslinked CMC-SB has been prepared successfully.

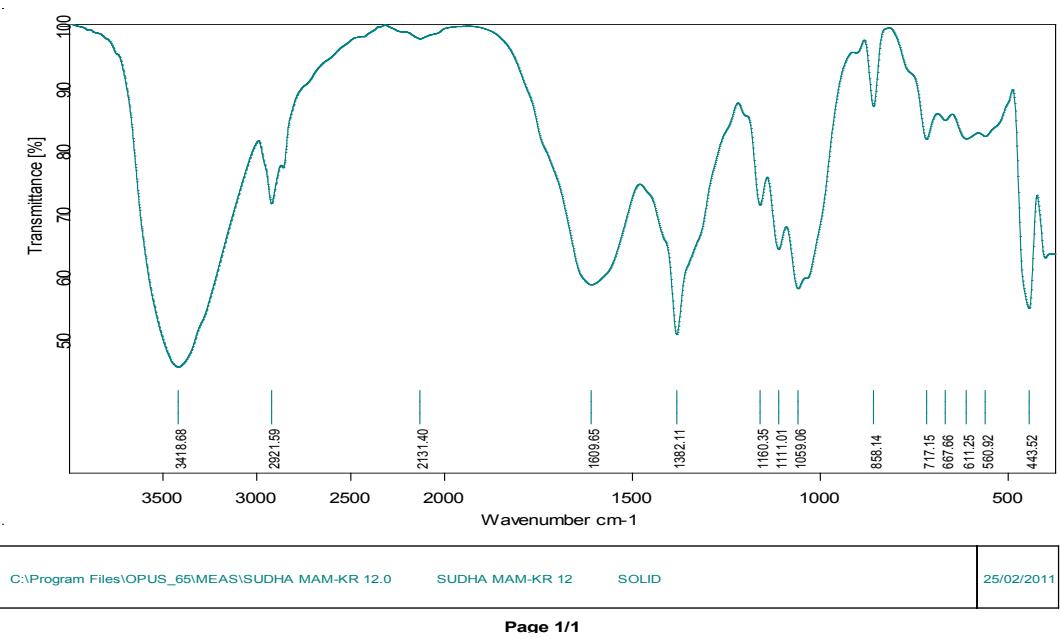

Fig. 3: FTIR spectrum of Carboxymethyl Chitosan/2, 3 -dimethoxy Benzaldehyde Schiff base derivative 


\section{XRD studies}

The X-ray diffraction of CMC, CMC-SB and Glu-CMC-SB were shown in Figure -5, 6 and 7. The peaks of $\mathrm{CMC}$ obtained at $2 \mathrm{è}=20^{\circ}, 29^{\circ}$ and $46^{\circ}$ were broad. For CMC-SB the peak was shifted to $2 \mathrm{è}=28^{\circ}, 47^{\circ}$ and $56^{\circ}$, this indicates the formation of Schiff base. The peaks are broad, which indicates that the prepared schiff base has semi crystalline nature. The XRD spectra of Glu -CMC-SB exhibits two broad peaks around $20^{\circ}$ and $40^{\circ}$, indicates that the sample is going form crystalline to amorphous nature ${ }^{17}$. Thus the interaction detected in this work decreases the membrane crystallinity.

\section{SEM Analysis}

The surface morphology of CMC, CMCSB and Glu-CMC-SB complexes were shown in the Figure-8. From the SEM image we conclude that $\mathrm{CMC}$ shows a homogeneous smooth surface and CMC-SB shows rough surface due to the addition of aromatic aldehyde. Further, the rough porous surface is increased due to the addition of
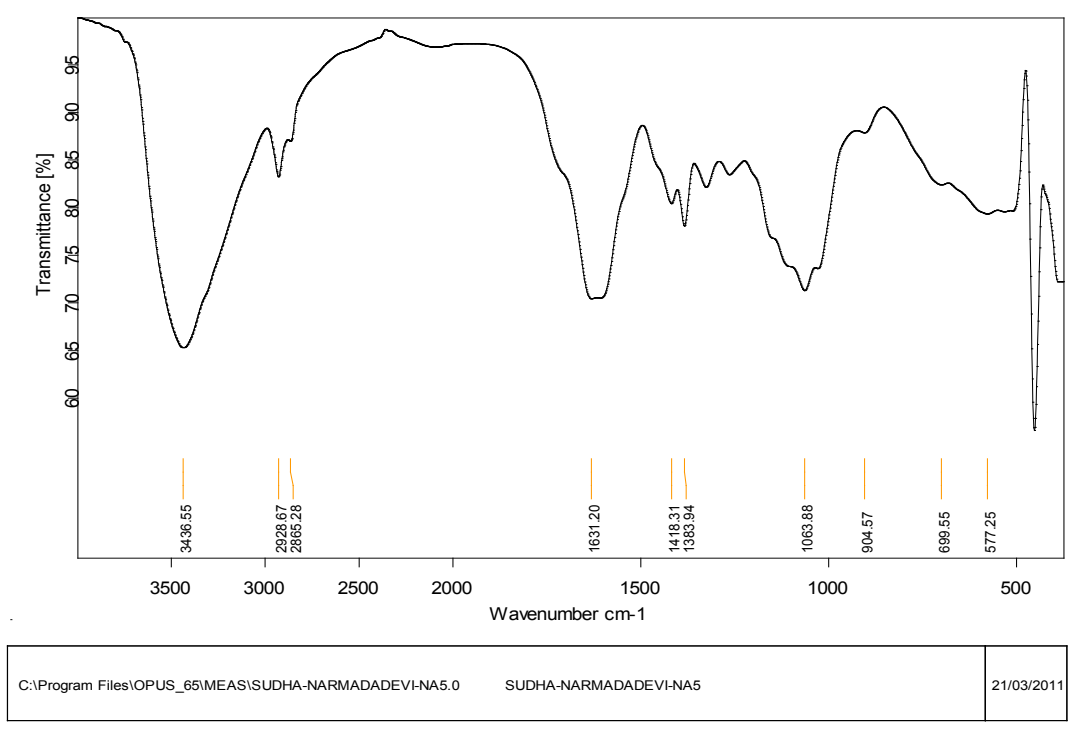

Page 1/1

Fig. 4: FTIR spectrum of Carboxymethyl Chitosan/2,3 -dimethoxy Benzaldehyde/Gluteraldehyde Schiff base derivative

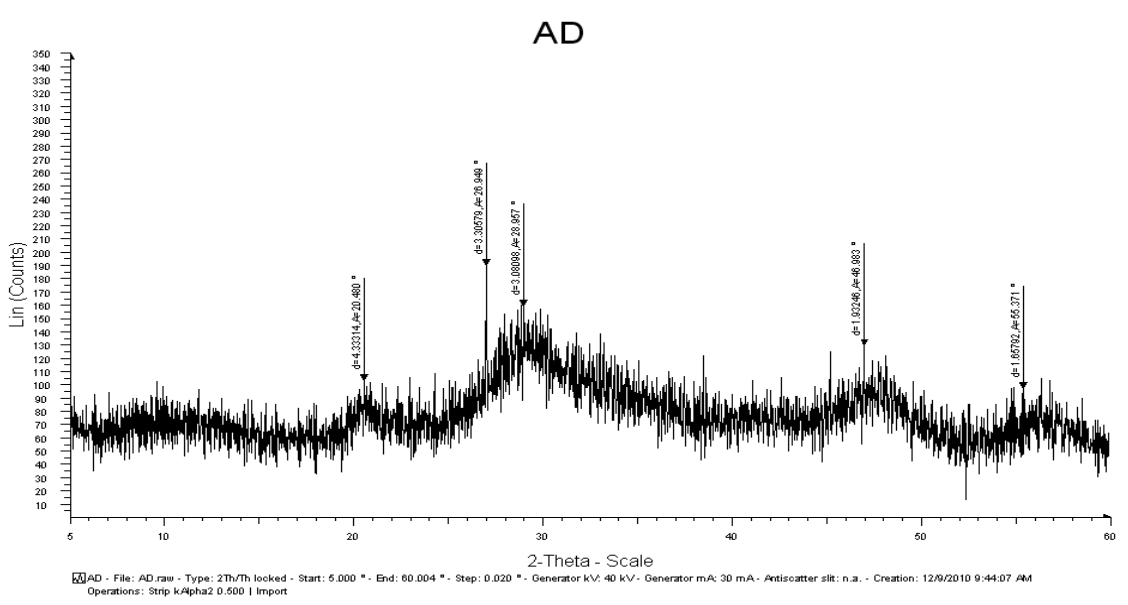

Fig. 5: XRD pattern of Carboxymethyl Chitosan 
gluteraldehyde. Comparing the bare Schiff base with its Glu-CMC-SB complexes, the image of cross linked Schiff base complex shows the rough and dense surfaces with large number of pores. These large rough surfaces were more suitable for greater adsorbing property and biomedical applications.

\section{Catalytic activity}

The efficiencies of the CMC-SB and Glu-CMC-SB complex as catalysts for oxidation of cyclohexane to cyclohexanol is shown in the Table -1 and Figure-9. When the reaction time is increased, the conversion percentage of cyclohexane is also increased. The results reveals the catalytic activity of CMC-SB complex was more pronounced at $12 \mathrm{~h}$ and the yield is $49 \%$ compared to the cross linked Schiff base complex (yield is $47 \%$ ) which shows a bright future in industrial applications.

\section{Removal of lead (II) and Cadmium (II) ions}

Optimum metal adsorption was determined by investigating the parameters such as initial concentration of metal ions, sorbent dosage, $\mathrm{pH}$ and contact time of solution at constant temperature.

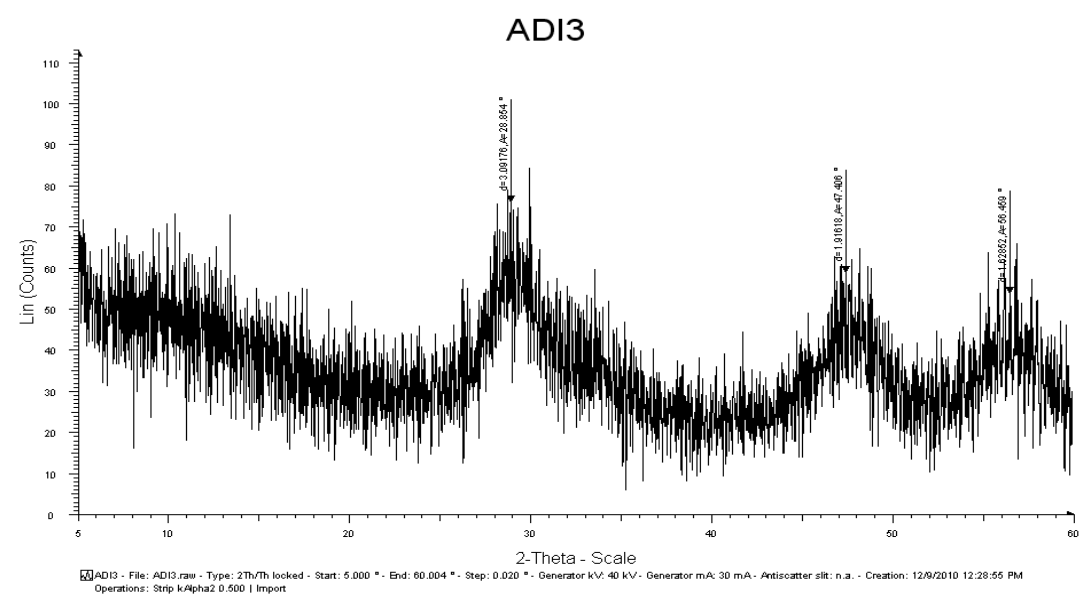

Fig. 6: XRD pattern of Carboxymethyl Chitosan/2,3 -dimethoxy Benzaldehyde Schiff base derivative

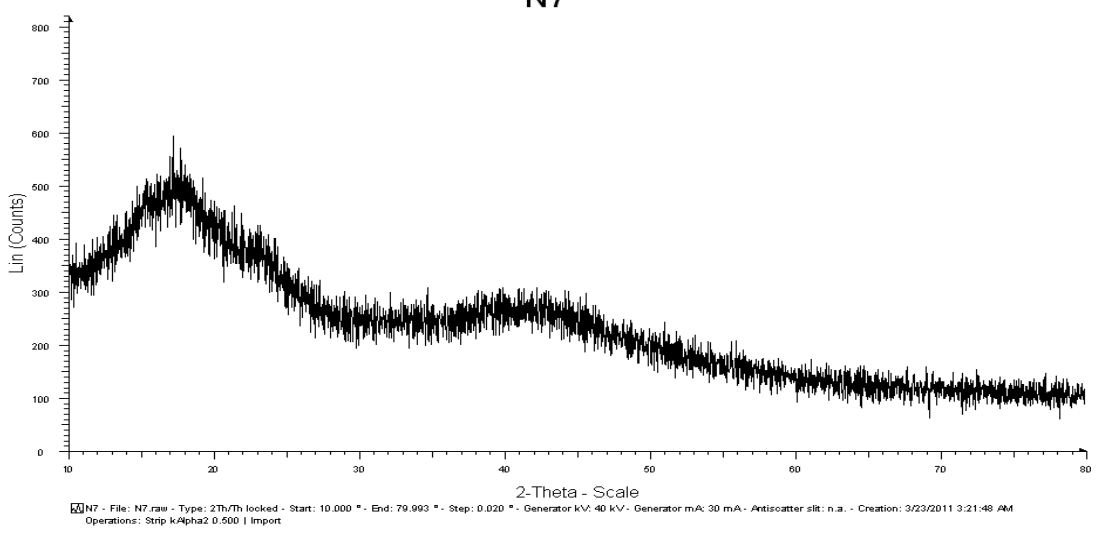

Fig. 7: XRD pattern of Carboxymethyl Chitosan/2,3 -dimethoxy Benzaldehyde/GluteraldehydeSchiff base derivative 
The equilibrium data were fit into Langumir model, Freundlich, Temkin and Dubinin - Radushkevich (D-R) adsorption isotherms.
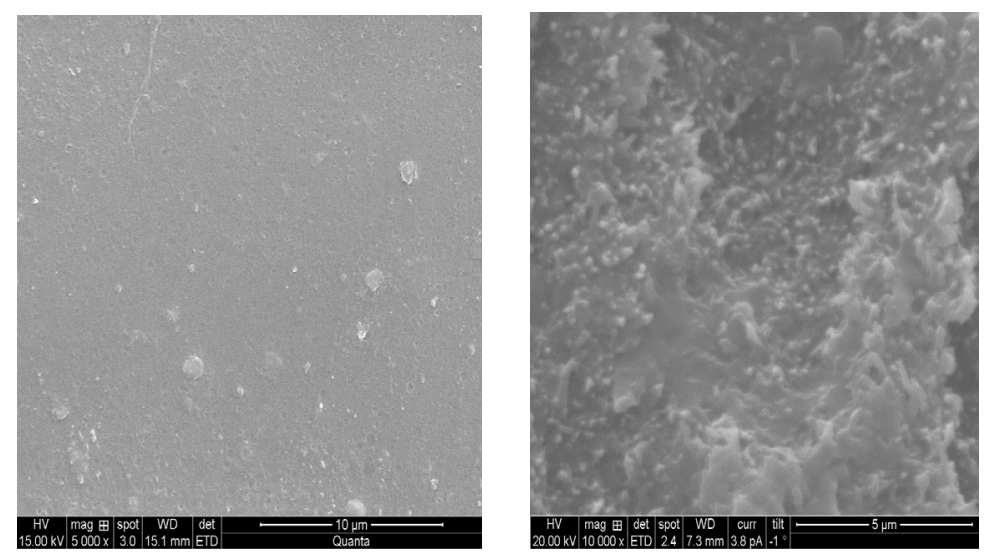

Fig. 8: SEM image of (a)CMC, (b) CMC-SB and (c) Crosslinked CMC-SB

Table 1: Catalytic activity of CMC-SB

\begin{tabular}{|c|c|c|c|}
\hline \multirow[t]{2}{*}{ Samples } & \multicolumn{3}{|c|}{$\%$ Conversion to Cyclohexanol } \\
\hline & 4Hrs & 8Hrs & $12 \mathrm{Hrs}$ \\
\hline CMC-SB & 27 & 34 & 49 \\
\hline Glu-CMC-SB & 23 & 32 & 47 \\
\hline
\end{tabular}

Table 2: Adsorption isotherm constant, Cmax and correlation coefficients

\begin{tabular}{lcccc}
\hline & \multicolumn{4}{c}{ Langmuir constants } \\
$\begin{array}{l}\text { Metal } \\
\text { ions }\end{array}$ & $\begin{array}{c}\mathbf{K}_{\mathrm{L}} \\
\left(\mathbf{d m}^{3} / \mathbf{g}\right)\end{array}$ & $\begin{array}{c}\mathbf{b} \\
(\mathbf{d m} / \mathbf{m g})\end{array}$ & $\begin{array}{c}\mathbf{C}_{\max } \\
(\mathbf{m g} / \mathbf{g})\end{array}$ & $\mathbf{R}^{2}$ \\
\hline $\mathrm{Pd}(\mathrm{II})$ & 0.8432 & 0.008432 & 100 & 0.772 \\
$\mathrm{Cd}(\mathrm{II})$ & 0.9814 & 0.009814 & 100 & 0.827 \\
\hline
\end{tabular}

Table 4: Coefficients of Temkin isotherm model

\begin{tabular}{lcccc}
\hline Metal & \multicolumn{5}{c}{ Temkin isotherm parameters } \\
ions & $\mathbf{B}(\mathrm{KJ} / \mathbf{m o l})$ & $\mathbf{A}_{\mathbf{T}}(\mathbf{L} / \mathbf{g})$ & $\mathbf{b}_{\mathbf{T}}$ & $\mathbf{R}^{\mathbf{2}}$ \\
& & & & \\
\hline $\mathrm{Pd}(\mathrm{II})$ & 0.01425 & 0.2324 & 173.86 & 0.8080 \\
$\mathrm{Cd}(\mathrm{II})$ & 0.01542 & 0.2398 & 160.67 & 0.842 \\
\hline
\end{tabular}

\section{Effect of adsorbent dose}

The adsorption dependence of $\mathrm{Pb}$ (II) and Cd (II) was studied by varying the amount of adsorbents from $1-6$ gms, while keeping the $\mathrm{pH}$

and contact time as constant. From the Figure-10 and 11 , the influence of adsorption process can be observed by increasing its adsorbent dosage. The removal efficiency increases with increase in the amount of adsorbent dosage; this is due to the greater availability of the exchangeable sites for the ions ${ }^{18}$. After a certain amount of adsorbent (5-6gms), there is no further increase in adsorption. This

Table 3: Coefficients of Freundlich isotherm model

\begin{tabular}{lccc}
\hline \multirow{2}{*}{$\begin{array}{l}\text { Metal } \\
\text { ions }\end{array}$} & \multicolumn{3}{c}{ Freundlich constants } \\
& $\mathbf{K}_{\mathbf{F}}(\mathbf{m g} / \mathbf{g})$ & $\mathbf{n}$ & $\mathbf{R}^{\mathbf{2}}$ \\
\hline $\mathrm{Pd}(\mathrm{II})$ & 2.2336 & 1.6529 & 0.988 \\
$\mathrm{Cd}(\mathrm{II})$ & 2.2699 & 1.5873 & 0.992 \\
\hline
\end{tabular}

Table 5: D-R Isotherm Parameters

\begin{tabular}{lcccc}
\hline \multicolumn{4}{c}{$\mathbf{D}-\mathbf{R}$ isotherm parameters } \\
$\begin{array}{l}\text { Metal } \\
\text { ions }\end{array}$ & $\begin{array}{c}\mathbf{q}_{\mathbf{s}} \\
(\mathbf{m g} / \mathbf{g})\end{array}$ & $\begin{array}{c}\mathbf{K}_{\text {ads }} \\
\left(\mathbf{m o l}^{2} / \mathbf{J}^{2}\right)\end{array}$ & $\begin{array}{c}\mathbf{E} \\
(\mathrm{KJ} / \mathrm{mol})\end{array}$ & $\mathbf{R}^{2}$ \\
\hline $\mathrm{Pd}(\mathrm{II})$ & 27.31 & $4 \times 10^{-6}$ & 0.35361 & 0.542 \\
$\mathrm{Cd}(\mathrm{II})$ & 28.80 & $4 \times 10^{-6}$ & 0.35361 & 0.563 \\
\hline
\end{tabular}


shows that the maximum adsorption has attained and hence the ions attached to the adsorbent and the amount of free ions remains constant ${ }^{19}$. The maximum \% removal of $\mathrm{Pb}^{2+}$ was $87.7 \%$ and 94.2 $\%$ in CMC-SB and Glu-CMC-SB respectively. In the removal of $\mathrm{Cd}$ (II) ions, the percentage of removal is $87.9 \%$ and $94.1 \%$ for CMC-SB and Glu-CMC-SB. The result reveals that the cross linked Schiff base complex exhibits more removal compared to the Schiff base.

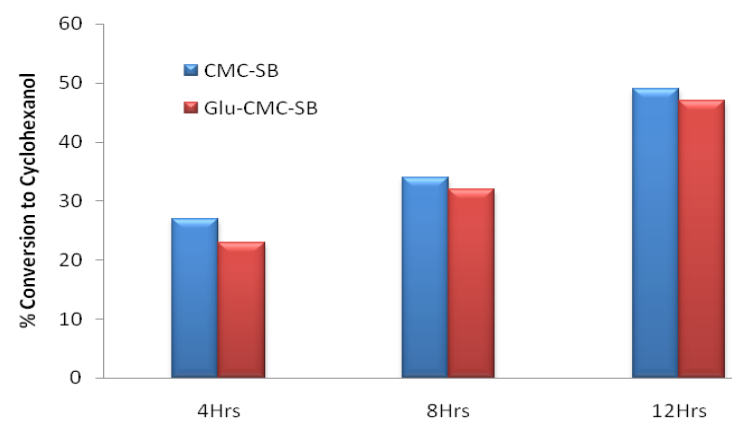

Fig. 9: Catalytic activity of CMC-SB

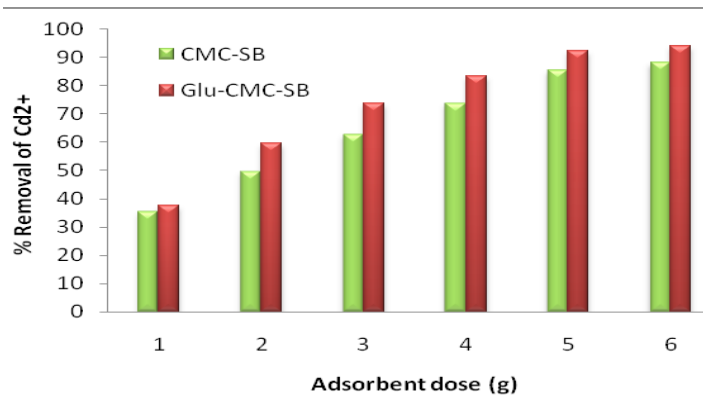

Fig. 11: Effect of adsorbent dose on the removal of $\mathrm{Cd}^{2+}$

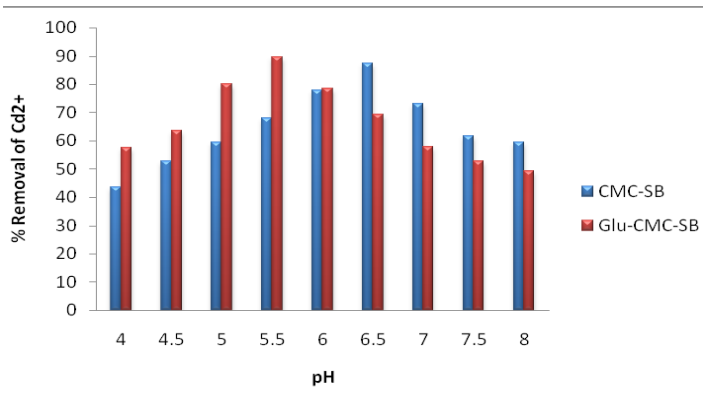

Fig. 13: Effect of $\mathrm{pH}$ on the removal of $\mathrm{Cd}^{2+}$

\section{Effect of pH}

The Figure - 12 and 13 shows the $\mathrm{pH}$ dependence in the removal efficiency of the lead and cadmium ions in the aqueous solution. Studies revealed that the system is strongly $\mathrm{pH}$ dependent, due to the nature of the chemical interactions with the functional group on the Carboxymethyl chitosan matrix. The optimum removal was obtained at $\mathrm{pH} 6$ for Schiff base complex and $\mathrm{pH} 5$ for cross linked Schiff base complex. With increase in the $\mathrm{pH}$ the adsorption also increases, due to the decrease in the competition between the $\mathrm{H}^{+}$and the lead and cadmium ions for the same functional group. After

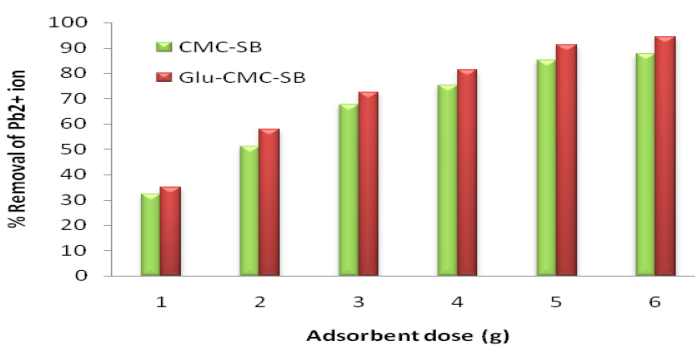

Fig. 10: Effect of adsorbent dose on the removal of $\mathrm{Pb}^{2+}$

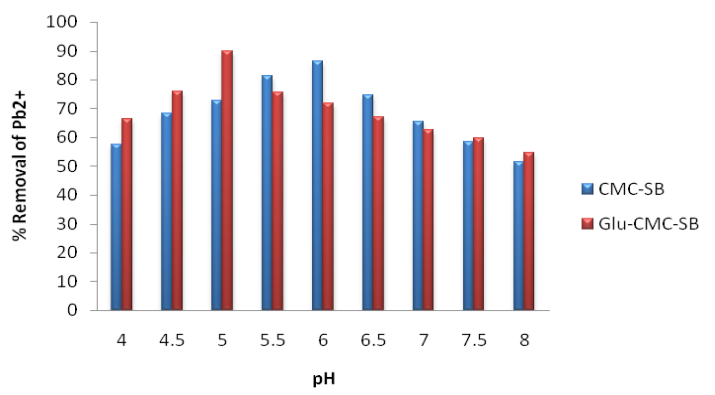

Fig. 12: Effect of $\mathrm{pH}$ on the removal of $\mathrm{Pb}^{2+}$

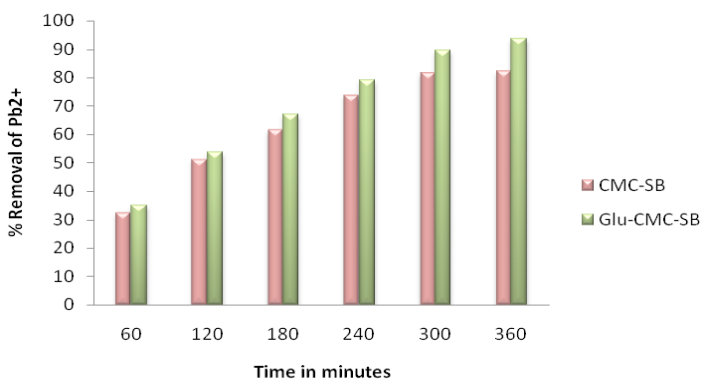

Fig. 14: Effect of contact time on the removal of $\mathrm{Pb}^{2+}$ 
the certain level of $\mathrm{pH}$, the adsorption decreases due the insoluble hydroxide ions precipitating from the solution making the adsorption studies impossible.

The Contact time is an important factor, which is useful for the wastewater treatment system. The influence of the contact time for the removal of the $\mathrm{Pb}^{2+}$ and $\mathrm{Cd}^{2+}$ ions was analysed by keeping the initial solution concentration $200 \mathrm{mg}$ Metal (II)/L, $\mathrm{pH}$ 5 \& 6 and adsorbent dosage $1 \mathrm{~g}$ as constant. The observed results are presented in Figure-14 \& 15. It was found that the removal efficiency of metal ions

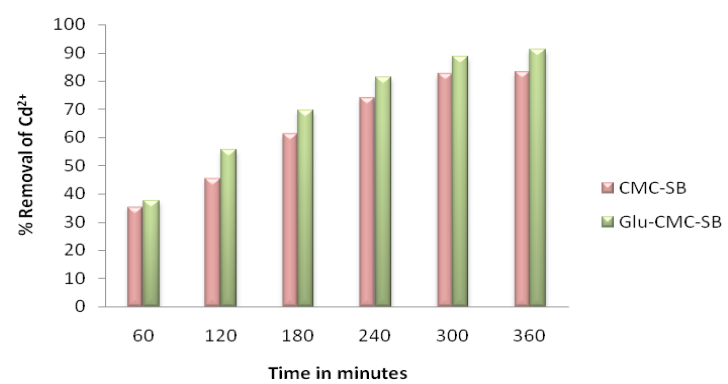

Fig. 15: Effect of contact time on the removal of $\mathrm{Cd}^{2+}$

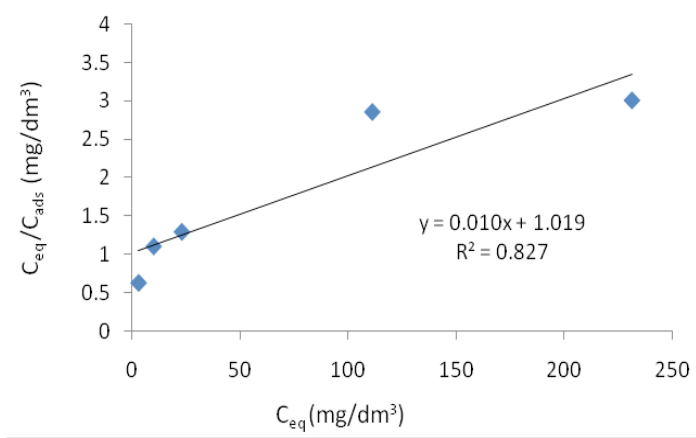

Fig. 17: Langmuir isotherm model for $\mathrm{Cd}^{2+}$

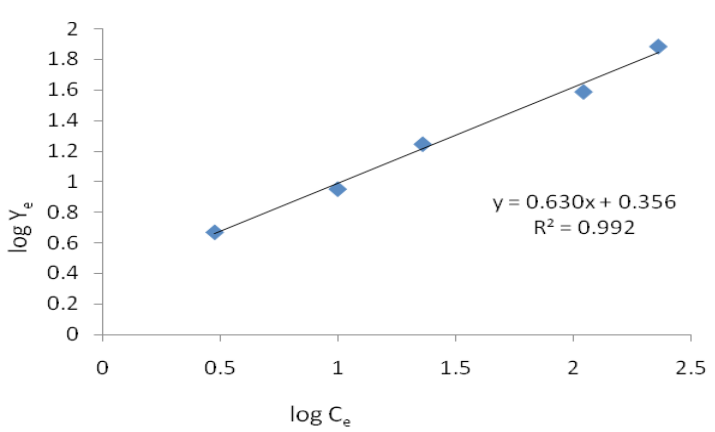

Fig. 19: Freundlich isotherm model for $\mathrm{Cd}^{2+}$ increased with increase in contact time to some extent, due to high transfer rate of the metal ions to the surface of the adsorbent particles. Further increases in contact time, the equilibrium have been attained and hence no further increase in adsorption $20-21$. Thus the results illustrated that the optimum contact time for maximum removal of $\mathrm{Pb}^{2+}$ and $\mathrm{Cd}^{2+}$ were $360 \mathrm{~min}$.

\section{Adsorption Isotherms}

The adsorption isotherm is fundamental in describing the interactive behaviour between solutes

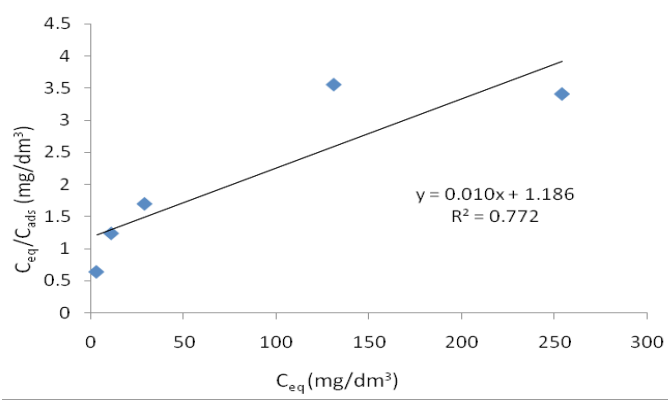

Fig. 16: Langmuir isotherm model for $\mathrm{Pb}^{2+}$

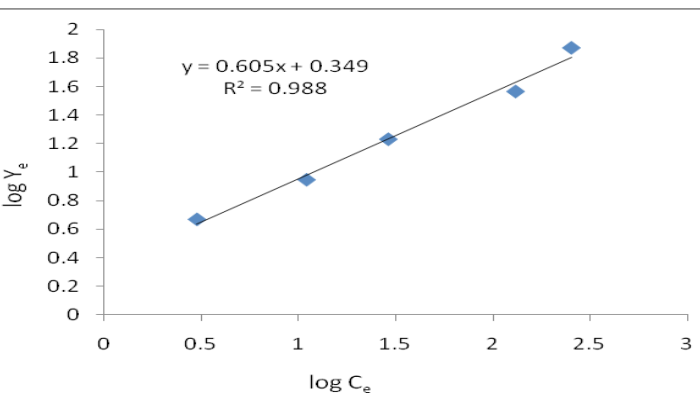

Fig. 18: Freundlich isotherm model for $\mathrm{Pb}^{2+}$

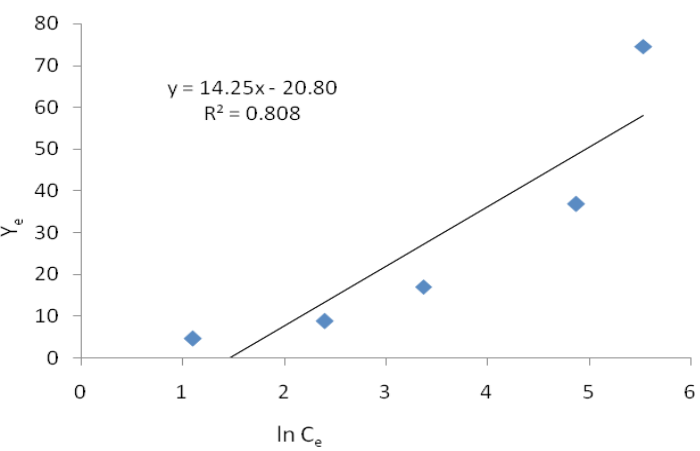

Fig. 20: Temkin isotherm model for $\mathrm{Pb}^{2+}$ 
and adsorbent, which express the surface properties and affinity of the adsorbent ${ }^{22}$. The adsorption isotherm and its kinetics of CMC-SB complex for the removal of $\mathrm{Pb}(\mathrm{II})$ is already reported in the literature ${ }^{11}$. Hence adsorption isotherm and kinetic study for the cross linking of CMC-SB complex is discussed below.

\section{Langmuir adsorption isotherm}

The Langmuir adsorption isotherm is one of the most widely used isotherms, proposed for the adsorption of a solid at a solid-liquid interface. It is assumed that each of which can adsorb one adsorbate molecule, i.e., monolayer adsorption

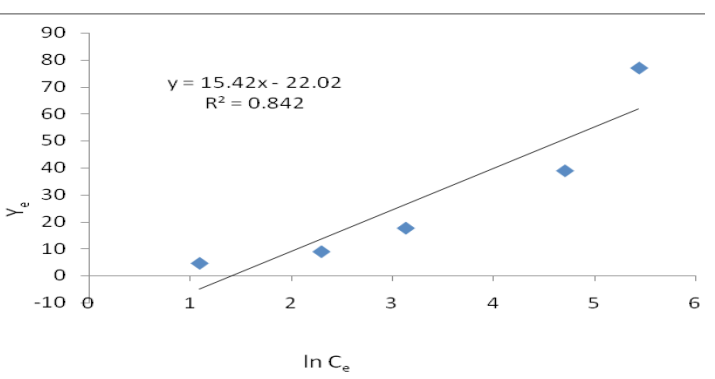

Fig. 21: Temkin isotherm model for $\mathbf{C d}^{2+}$

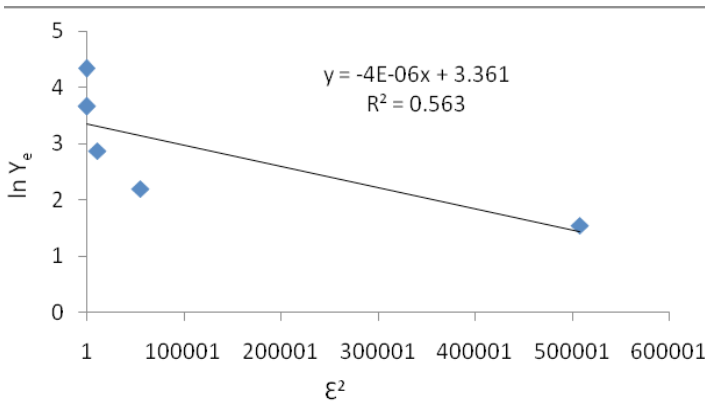

Fig. 23: D-R isotherm model for $\mathrm{Cd}^{2+}$

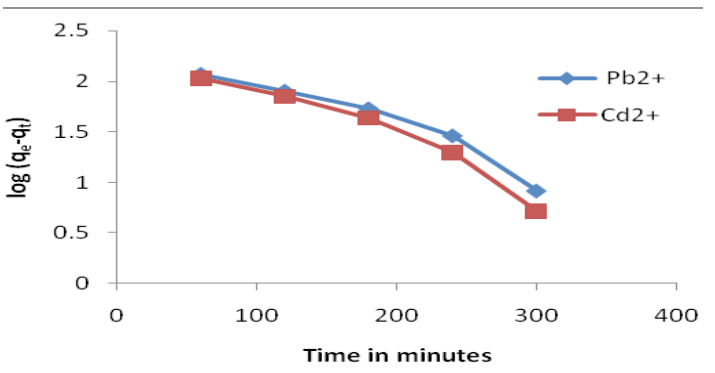

Fig. 25: Pseudo-first order kinetics model made up of elementary sites 23. Another assumption is that there is no reaction between molecules adsorbed on neighbouring sites 24 .

The linearised Langmuir isotherm allows the calculation of adsorption capacities and Langmuir constant " $\mathrm{b}$ " and " $\mathrm{K}_{\mathrm{L}}$. With the help of the slope and intercept of linear plot of $C_{\text {eq }} / C_{\text {ads }}$ against $C_{\text {eq }}$ shown in the Figure-16 \& 17, the Langmuir constants $\mathrm{K}_{\mathrm{L}}$ and $\mathrm{b}$ can be calculated and given in the Table- 2 .

\section{Freundlich isotherm}

The linearised Freundlich equation plot of $\log q_{e} v s \log C_{e}$ yielded a straight line as shown

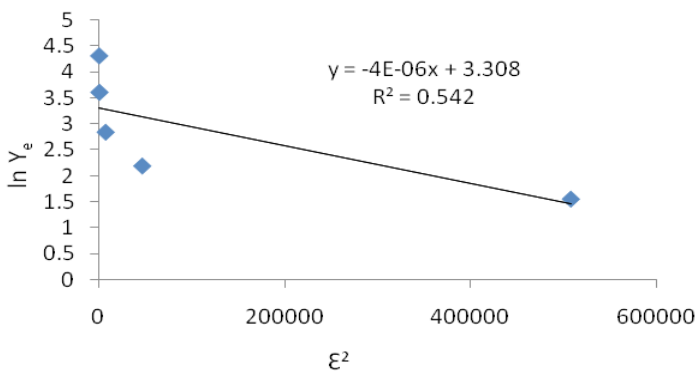

Fig. 22: $\mathrm{D}-\mathrm{R}$ isotherm model for $\mathbf{P b}^{2+}$

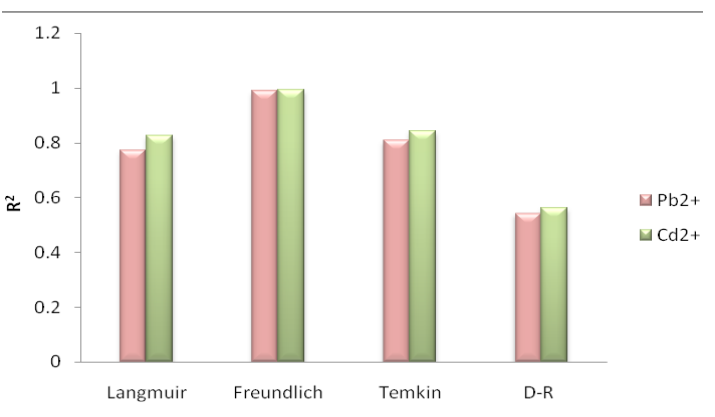

Fig. 24: Comparison between Correlation Coefficients of four Isotherms

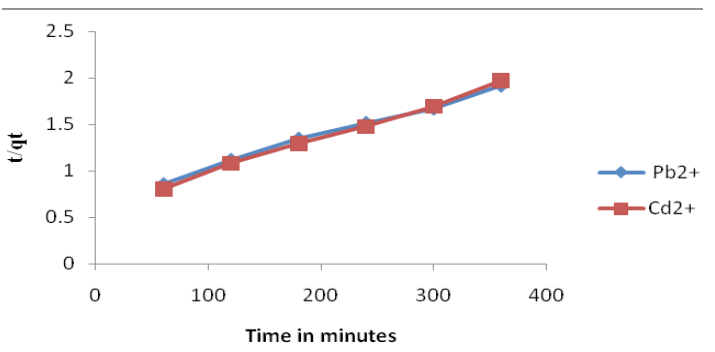

Fig. 26: Pseudo-second order kinetics model 
Table 6: Comparison between Lagergren pseudo-first-order and pseudo-second-order kinetic models

\begin{tabular}{|c|c|c|c|c|c|c|c|}
\hline \multirow[b]{2}{*}{$\begin{array}{l}\text { Metal } \\
\text { ion }\end{array}$} & \multicolumn{3}{|c|}{$\begin{array}{l}\text { Pseudo-first-order } \\
\text { kinetic model }\end{array}$} & \multirow{2}{*}{$\begin{array}{c}\text { Experimental } \\
\text { valueqe } \\
(\mathrm{mg} / \mathrm{g})\end{array}$} & \multicolumn{3}{|c|}{$\begin{array}{l}\text { Pseudo-second order } \\
\text { kinetic model }\end{array}$} \\
\hline & $\begin{array}{c}\mathrm{qe} \\
(\mathrm{mg} / \mathrm{g})\end{array}$ & $\begin{array}{c}\mathbf{k}_{1} \\
\left(\min ^{-1}\right)\end{array}$ & $\overline{\mathbf{R}^{2}}$ & & $\begin{array}{c}\mathrm{qe} \\
(\mathrm{mg} / \mathrm{g})\end{array}$ & $\begin{array}{l}\mathbf{k}_{2}\left(\mathbf{g ~ m g}^{-1}\right. \\
\left.\text { min }^{-1}\right)\end{array}$ & $\overline{\mathrm{R}^{2}}$ \\
\hline$\overline{\mathrm{Pb}(\mathrm{II})}$ & 274.79 & 0.09212 & 0.927 & 187 & 333.33 & $1.5075 \times 10^{-5}$ & 0.995 \\
\hline $\mathrm{Cd}(\mathrm{II})$ & 289.73 & 0.01152 & 0.939 & 182 & 333.33 & $1.3119 \times 10^{-5}$ & 0.993 \\
\hline
\end{tabular}

in Figure -18 \& 19 and Table-3. The Freundlich isotherm model proposed a monolayer adsorption with a heterogeneous energetic distribution of active sites, and/or interactions between adsorbed species. Using mathematical calculation that an ' $n$ ' value between 1 and 10 represents beneficial adsorption 25 .

\section{Temkin Isotherm}

The Temkin isotherm takes into account the interactions between adsorbents and metal ions to be adsorbed and is based on the adsorption, that the free energy of adsorption is simply a function of surface coverage. By plotting the quantity adorbed qe against $\ln \mathrm{Ce}$ and the constants were determined from the slope and intercept shown in Figure-20 \& 21 and calculated parameters in Table-4. From the figures, we determine the heat of adsorption (B) for $\mathrm{Pb}$ (II) and Cd (II) is $14.25 \mathrm{~J} / \mathrm{mol}$ and $15.42 \mathrm{~J} / \mathrm{mol}$. The maximum binding energy $\left(\mathrm{A}_{\mathrm{T}}\right)$ for $\mathrm{Pb}$ (II) and $\mathrm{Cd}$ (II) is 0.2324 and $0.2398 \mathrm{~L} / \mathrm{g}$.

\section{Dubinin - Radushkevich (D - R) sorption isotherm}

Dubinin - Radushkevich model (Dubinin and Radushkevich, (1947) is postulated within a sorption space close to the sorbent surface to evaluate the sorption free energy and to help to determine the nature of bonding either physisorption (or) chemisorptions. By plotting the quantity adsorbed ${ }^{2}$ against $\operatorname{InYe}$ and $\mathrm{K}_{\mathrm{ads}}$ shown in Figure-22 \& 23, $\mathrm{q}_{\mathrm{s}}$ and $\mathrm{E}$ were determined from the slope, intercept and given in Table - 5 .

\section{Comparison between Adsorption Isotherms}

The Table-2-5 illustrates the linear regression coefficient of four isotherms. On comparing these isotherm models in Figure -24, the observed $R^{2}$ values of Freundlich isotherm (0.988 and 0.992) better describes the adsorption process very effectively when compared to the other models. Hence Freundlich model was followed and multilayer adsorption was suggests for the removal of metal ions by the Glu-CMC-SB. Further it can be proved by comparing the Temkin and D-R isotherm ' $E$ ' values, the mean free energy and the heat of adsorption values for $\mathrm{Pb}$ (II) and $\mathrm{Cd}$ (II) ions are lower than $20 \mathrm{KJ} /$ mol. According to Atkins, when the energy values are lower than $20 \mathrm{KJ} / \mathrm{mol}$, confirms the physisorption mechanism is followed. Physisorption is also called non-specific adsorption which occurs as a result of long range weak Van der waals forces between adsorbates and adsorbents 26

\section{Adsorption Kinetics}

The adsorption data of lead (II) and Cd (II) ion uptake by Glu-CMC-SB complex was fitted using Lagregren pseudo first order (Figure - 25) and pseudo second order model (Figure-26).

A comparison between two kinetic models suggested in Table -6 and Figure -25 \& 26, the correlation coefficient $\left(R^{2}\right)$ for the pseudo-second order kinetic model is much higher in comparison to pseudo-first order model. The close agreement between the experimental $q_{e} \mathrm{mg} / \mathrm{g}$ ) values and the estimated $q_{e}(\mathrm{mg} / \mathrm{g})$ values from pseudo-second order kinetic model. These facts suggest that obtained kinetic data followed the pseudo-second order kinetic model ${ }^{27}$.

\section{CONCLUSION}

The cross linked Carboxymethyl chitosan Schiff base complex was successfully synthesized using gluteraldehyde. The FTIR result proves the cross linking of Schiff base and XRD shows that the sample goes from crystalline to amorphous nature, 
which makes the material suitable for waste water treatment. The SEM results clearly indicates the rough and porous nature of cross linked sample compared to the other samples, which increases the adsorption process and helps in the removal of heavy metals. All these results reveals that the prepared crosslinked Carboxymethyl chitosan Schiff base acts as a efficient biosorbent with good metalbinding capacity for the removal of heavy metals like lead and cadmium ions from aqueous solutions, The adsorption efficiency of the Crosslinked biopolymer can be further used for the study of waste water tannery effluent. From the regression coefficient, we conclude the adsorption follows Freundlich model rather than the others. The adsorption follows the physisorption also concluded from the Temkin and D-R models. Through kinetic studies we confirmed that the adsorption process follows pseudo second order kinetic model. The oxidation of cyclohexane was performed and it also increased upto $12 \mathrm{~h}$, which is very useful in industrial applications in future.

\section{REFERENCES}

1. Kim, S,J,; Shin, S,R,; Lee, Y,M,; Kim, S,I. Journal of Applied Polymer Science. 2003, 87(12),2011-2015.

2. Lei, C,X,; Hu, S,Q,; Shen, G,L,; Yu, R,Q. Talanta. 2003, 59 (5), 981-993.

3. Muzzarelli, R,A,A. Carbohydrate Polymers. 1988, 8(1), 1-21.

4. Qin, Y. Journal of Applied Polymer science. 2006, 99(6), 3110-3115

5. Lu, J,;Vecchi, G,A,;Reichler, T. Geophysical Research Letters.2007, 34, L06805,

6. Mourya, V,K,; Inamdar, N,N,; Tiwari, A. Advanced materials letters. 2010, 1(1),1133.

7. Oytron MonteiroJr, A,C,; Claudio Airoldi. International journal of Biological Macromolecules. 1999, 26 (2-3), 119-128.

8. Choong, J,;Wolfgang, H,H. Water Research. 2003, 37(19), 4770-4780.

9. Wang, S,; Xu, X,; Yang, J,; Gao, J. Fuel Processing Technology. 2011, 92(3), 486492.

10. Suguna, M,; Kumar, N,S,; Reddy, A,S,; Boddu, V,M,; Krishnaiah, A. Canadian Journal of Chemical Engineering. 2011, 89(4), 833843.

11. Moganavally, $P$;; Suresh, R,; Deepa, M,; Sudha, P,N. Journal of Chemical and Pharmaceutical Research. 2015, 7(5), 1013-1022.

12. Guinesi, L,S,; Cavalheiro, E,T,G. Thermochim. Acta. 2006, 444, 128-133.

13. Chen, X,G,; Park, H,J. Carbohydrate Polymers. 2003, 53(4), 355-359.

14. Jonathan Knaul, Z,; Samuel Hudson, M,; Katherine Creber, A,M. Journal of Polymer Science Part B: Polymer Physics. 1999,
37(11),1079-1094.

15. Von Rao CNR, Chemical Application of Infrared Spectroscopy. New York, London: Academic Press, 1963.

16. Riham Mohamed, R,; Fekry, A,M.. International Journal of Electrochemical Science.2011, 6, 2488-2508.

17. Monteiro, A,C,; Airoldi, C. International Journal of Biological Macromolecules. 1999, 26 (2-3), $119-128$.

18. Nomanbhay, S,F,; Palanisamy, K. Electronic Journal of Biotechnology. 2005, 8 (1): 4453.

19. Onsoyen, E,; Skaugrad, O. Journal Chemical Technology and Biotechnology. 1990, 49, 395404.

20. Sheeba Thavamani, S,; Rajkumar, R. Research Journal of Chemical Sciences. 2013, 3(8), 44-48.

21. Chiou, M,S,; Li, H,Y. Chemosphere. 2003, 50(8), 1095-1105.

22. Ofomoja, A,E,; Ho, Y,S. Dyes and Pigments.2007, 74(1), 60-66.

23. Ho, Y,S,; Hung, C,T; Huang, H,W. Process Biochemistry. 2002, 37(12), 1421-1430.

24. Chao, A,C,; Shyu, S,S,; Lin, Y,C,; Mi, F,L. Bioresource Technology.2004, 91(2), 15762.

25. Jonathan Febrianto,; Aline Natasia Kosasih,; Jaka Sunarso,; Yi-Hsu Ju,; Nani Indraswati,; Suryadi Ismadji. Journal of Hazardous Materials. 2009, 162(2-3), 616- 645.

26. Atkins, P. Physical chemistry 6th Edition, Oxford University Press, 1999, 857 - 864.

27. Hanif, A,; Bhatti, H,N,; Hanif, M,A. Ecological Engineering. 2009, 35(10), 1427-1434. 